\title{
Cytotoxic effects of pyrrolidine dithiocarbamate in small-cell lung cancer cells, alone and in combination with cisplatin
}

\author{
SHINICHI TAHATA ${ }^{1}$, BO YUAN ${ }^{1,2}$, HIDETOMO KIKUCHI $^{1}$, NORIO TAKAGI ${ }^{2}$, \\ TOSHIHIKO HIRANO ${ }^{3}$ and HIROO TOYODA ${ }^{1}$
}

\begin{abstract}
Departments of ${ }^{1}$ Clinical Molecular Genetics, ${ }^{2}$ Applied Biochemistry, and ${ }^{3}$ Clinical Pharmacology, School of Pharmacy, Tokyo University of Pharmacy and Life Sciences, Hachioji, Tokyo 192-0392, Japan
\end{abstract}

Received May 20, 2014; Accepted July 1, 2014

DOI: 10.3892/ijo.2014.2564

\begin{abstract}
The cytocidal effect of pyrrolidine dithiocarbamate (PDTC) was investigated by focusing on cell viability, cell cycle arrest and apoptosis induction in small-cell lung cancer (SCLC) cell lines (NCI-H196 and NCI-H889). PDTC exhibited a much stronger dose-dependent cytotoxic activity against NCI-H196 compared to NCI-H889, while no such activity was observed in normal human embryonal lung fibroblast MRC-5 cells. Cell cycle arrest in S phase paralleled with suppression of c-myc expression without accompanying DNA fragmentation was observed in NCI-H196 cells. A transient increase in the intracellular ROS accompanied with an alteration of expression of oxidative stress-related genes was also confirmed in NCI-H196 cells. Furthermore, the addition of $\mathrm{N}$-acetyl-L-cysteine (NAC), a free radical scavenger, not only abolished PDTC-trigger alterations of expression of these oxidative-related genes, but also almost completely abrogated PDTC-induced reduction in cell viability and morphological changes associated with cell damage. These results thus suggest that PDTC-induced cytotoxicity is attributed to its pro-oxidant activity. PDTC-induced cytotoxicity was further enhanced by $\mathrm{CuCl}_{2}$, however, abolished by bathocuproine disulfonate (BCPS), a non-permeable copper-specific chelator, supporting the plausibility that accumulation of intracellular $\mathrm{Cu}$ plays an important role in the cytotoxicity. Importantly, we demonstrated for the first time that PDTC downregulated the expression of ATP7A, known to be responsible for $\mathrm{Cu}$ efflux, but did not affect the expression of CTR1, known as a copper uptake transporter. Intriguingly, combination of much lower
\end{abstract}

Correspondence to: Dr Bo Yuan or Dr Hiroo Toyoda, Department of Clinical Molecular Genetics, School of Pharmacy, Tokyo University of Pharmacy and Life Sciences, 1432-1 Horinouchi, Hachioji, Tokyo 192-0392, Japan

E-mail: yuanbo@toyaku.ac.jp

E-mail: toyoda-h@toyaku.ac.jp

Key words: small-cell lung cancer, pyrrolidine dithiocarbamate, $\mathrm{S}$ phase arrest, ROS, copper-transporting P-type adenosine triphosphatase (ATP7A), cisplatin dose of cisplatin $(5 \mu \mathrm{M})$ and non-toxic dose of PDTC $(0.1 \mu \mathrm{M})$ synergistically induced a significant cytotoxicity in NCI-H196 cells. Given that ATP7A plays a critical role in the resistance of platinum-drug (such as cisplatin) representing a first-line treatment for SCLC, PDTC could be a promising candidate of adjunct therapeutic reagent for the patients requiring treatment with platinum-based regimens.

\section{Introduction}

Lung cancer has been and remains one of the most common malignancy in the world with an estimated 1.6 million new cases per annum (1). Small-cell lung cancer (SCLC), which constitutes between 10 and $15 \%$ of all lung neoplasm and is different from non-small-cell lung cancer (NSCLC) types in that it has neuroendocrine features, grows more rapidly, spreads earlier and has a lower cure rate $(1,2)$. Furthermore, SCLC metastasizes rapidly to distant sites within the body and is most often discovered after it has spread extensively $(1,3)$.

Whilst SCLC is initially sensitive to chemotherapy and radiotherapy, relapse is almost inevitable and the efficacy of treatment beyond first-line therapy diminishes as it becomes increasingly resistant to treatment (1-3). Although continuous efforts to improve clinical outcomes in patients with SCLC by progressing clinical trials with novel promising drugs are ongoing, platinum (such as cisplatin)-etoposide doublets still represent the gold standard of a first-line therapy (1). Furthermore, the 5-year survival rates have not improved significantly over the last 40 years and have currently plateaued, although advance in diagnosis and treatment have resulted in improved survival of other solid-tumor malignancies (1). Therefore, there is an obvious need to develop new therapeutic strategies for SCLC.

Pyrrolidine dithiocarbamate (PDTC), a thiol compound derived from dithiocarbamates, was initially described as an antioxidant agent and reported to induce cytotoxicity in some tumor cell lines $(4,5)$. On the other hand, PDTC has been described to act as a pro-oxidant agent (6-9). In fact, its pro-oxidant activity has been demonstrated to induce growth inhibition and cell death in rat cortical astrocytes (6), a human pancreatic adenocarcinoma cell line, PaGa44 (10) and promyelocytic leukemic cell line, HL-60 (11), respectively. It should be noted that PDTC has been demonstrated to sensitize 
human cervical cancer line and metastatic renal cell carcinoma to cisplatin $(12,13)$. As mentioned above, cisplatin-based regimens have become and remain the first-line treatment for SCLC from the 1980s $(14,15)$. Therefore, we hypothesize that PDTC may be a promising candidate of adjunct therapeutic reagent for SCLC. However, the effect of PDTC in SCLC cell lines, alone or in combination with cisplatin, has not yet been investigated.

Increased intracellular $\mathrm{Cu}$ content has been associated with PDTC-mediated cytotoxicity due to its ionophore properties $(6,9,11)$. Furthermore, the presence of $\mathrm{CuCl}_{2}$ has been demonstrated to potentiate the cytotoxic effects of PDTC in rat cortical astrocytes and HL-60 cells $(6,11)$. Intracellular $\mathrm{Cu}$ homeostasis is well known to be maintained by $\mathrm{Cu}$ transporters including copper-transporting P-type adenosine triphosphatase (ATP7A) responsible for $\mathrm{Cu}$ efflux, and copper transporter 1 (CTR1) responsible for $\mathrm{Cu}$ uptake (16). Moreover, ATP7A has been reportedly associated with platinum drug resistance in various types of solid tumors (16-18). It is especially noteworthy that ATP7A plays a critical role in cisplatin-resistance of NSCLC, and is a negative prognostic factor of NSCLC patients treated with platinum-based chemotherapy (19-21). However, to our knowledge, little is known about the expression of $\mathrm{Cu}$ transporters in SCLC cell lines as well as the impact of PDTC on their expression.

In the present study, we investigated first the cytocidal effects of PDTC on SCLC cell lines in view of growth inhibition, cell cycle arrest and apoptosis induction. We further evaluated whether oxidative stress is involved in the cytocidal effects by determining alterations in intracellular reactive oxygen species (ROS) level along with expression levels of oxidative-related genes. At the same time, the effect $N$-acetylL-cysteine (NAC), a free radical scavenger, on PDTC-mediated cytotoxicity was also evaluated. We further investigated the cytocidal effect of PDTC in combination with $\mathrm{CuCl}_{2}$ in the presence or absence of bathocuproine disulfonate (BCPS), a non-permeable copper-specific chelator, in order to verify whether $\mathrm{Cu}$ is involved in the cytocidal effect. Importantly, we investigated for the first time the effect of PDTC on the expression levels of copper transporters such as ATP7A and CTR1, and further evaluated the effects of cisplatin in combination with non-toxic dose of PDTC on SCLC cell lines.

\section{Materials and methods}

Materials. PDTC, RPMI-1640 medium, $\mathrm{CuCl}_{2}$, NAC, and ISOGEN (Wako Pure Chemical Industry, Osaka, Japan); fetal bovine serum (FBS) (Nichirei Biosciences, Tokyo, Japan); agarose X (Nippon Gene, Tokyo, Japan); dichlorofluorescin diacetate (DCFH-DA) (Invitrogen, Carlsbad, CA, USA); propidium iodide (PI), ribonuclease A (RNaseA), 2,3-bis(2-methoxy-4-nitro-5-sulfophenyl)-5-[(phenylamino) carbony]-2H-tetrazolium hydroxide (XTT), BCPS and cisplatin (Sigma-Aldrich, St. Louis, MO, USA) were purchased from indicated suppliers.

Cell culture and treatment. Human SCLC cell lines (NCIH196 and NCI-H889) and normal human embryonal lung fibroblast MRC-5 cells were obtained from the American Type Culture Collection (ATCC, Manassas, VA, USA). SCLC cell lines and MRC-5 cells were cultured in RPMI-1640 medium and Eagle's minimum essential medium (MEM), respectively, supplemented with $10 \%$ heat-inactivated FBS, $100 \mathrm{U} /$ $\mathrm{ml}$ of penicillin and $100 \mu \mathrm{g} / \mathrm{ml}$ of streptomycin at $37^{\circ} \mathrm{C}$ in a humidified atmosphere $\left(5 \% \mathrm{CO}_{2}\right.$ in air). Cells were treated with indicated concentrations of PDTC for the indicated time-points. In order to investigate whether oxidative stress is involved in PDTC-induced cytotoxicity, cells were treated with 0.3 or $1 \mu \mathrm{M}$ PDTC in the presence or absence of 1 or $2 \mathrm{mM}$ NAC for $24 \mathrm{~h}$. Moreover, in order to clarify whether copper ions are implicated in the PDTC-induced cytotoxicity, cells were treated with $\mathrm{CuCl}_{2}(10 \mu \mathrm{M})$ and BCPS $(50 \mu \mathrm{M})(\mathrm{a}$ non-permeable copper-specific chelator), alone or in combination, for $3 \mathrm{~h}$ prior to treatment with 0.1 and $0.3 \mu \mathrm{M}$ PDTC in the presence or absence of these reagents. Cells were also treated with $5 \mu \mathrm{M}$ cisplatin in the presence or absence of $0.1 \mu \mathrm{M}$ PDTC for $24 \mathrm{~h}$ to investigate whether PDTC sensitize SCLC cell lines to cisplatin. Cell viability was measured by the XTT assay as described previously (22). $\mathrm{IC}_{50}$ value of PDTC was $\sim 0.3 \mu \mathrm{M}$ calculated from the cell proliferation inhibition curve of NCI-H196 cells after 24-h treatment.

DNA fragmentation analysis. DNA fragmentation analysis was carried out according to a method described previously (23). Briefly, DNA samples [ 20 $\mu \mathrm{g}$ DNA/20 $\mu \mathrm{l}$ TE buffer $(10 \mathrm{mM}$ Tris-HCl, pH 7.8, 1 mM EDTA)] and a Tracklt ${ }^{\mathrm{TM}} 100$ bp DNA Ladder (Invitrogen) as a DNA size marker were electrophoresed, respectively, on a $2 \%$ agarose $\mathrm{X}$ gel, and visualized by ethidium bromide staining, followed by viewing under UV Light Printgraph (ATTO Corp., Tokyo, Japan).

Cell cycle analysis. After treatment with the $\mathrm{IC}_{50}$ value of PDTC at $0.3 \mu \mathrm{M}$ for $24 \mathrm{~h}$, cell cycle analysis was performed using a FACSCanto flow cytometer (Becton-Dickinson, CA, USA) according to methods reported previously with modifications $(24,25)$. A total of 10,000 events were acquired and Diva software and ModFit LT ${ }^{\mathrm{Tм}}$ Ver.3.0 (Verity Software House, ME, USA) were used to calculate the number of cells at each sub- $G_{1}, G_{0} / G_{1}, S$ and $G_{2} / M$ phase fraction.

\section{Reverse transcription-polymerase chain reaction (RT-PCR)} analysis. Total RNA isolation and complementary DNA were prepared according to methods described previously with modifications (23). Total RNA was extracted from cells using an RNA extraction kit, ISOGEN. Complementary DNA was synthesized from $1 \mu \mathrm{g}$ of RNA using 100 pmol random primer and $50 \mathrm{U}$ M-MLV RT in a total volume of $20 \mu \mathrm{l}$, according to the manufacturer's instructions. PCR was performed according to the methods previously described (23) using a Takara Thermal Cycler MP (Takara Shuzo Co., Osaka, Japan). DNA sequences of PCR primers and optimal conditions for PCR are shown in Table I. PCR primers were purchased from Sigma-Aldrich (Hokkaido, Japan). PCR products and 100 bp DNA Ladder were electrophoresed on a $2 \%$ UltraPure $^{\mathrm{TM}}$ agarose gel (Invitrogen), respectively, and visualized by ethidium bromide staining, followed by viewing under UV Light Printgraph. The relative expression levels of target gene/ $\beta$-actin gene were calculated as the ratios against those at 0 -time using Image $1.46 \mathrm{~m}$ (Wayne Rasband, USA). 
Table I. RT-PCR analysis.

A, PCR primers and optimal numbers of PCR cycle

\begin{tabular}{lll}
\hline Target mRNA & & DNA sequence of PCR primer \\
\hline Cox-2 & Sense & 5'-TTCAAATGAGATTGTGGGAAAATTGCT-3' \\
& Antisense & 5'-AGATCATCTCTGCCTGAGTATCTT-3' \\
HO-1 & Sense & 5'-CCAGCAACAAAGTGCAAGATTC-3' \\
& Antisense & 5'-CTGCAGGAACTGAGGATGCTG-3' \\
Mn-SOD & Sense & 5'-GCACTAGCAGCATGTTGAGCCG-3' \\
& Antisense & 5'-CAGTTACATTCTCCCAGTTGATTAC-3' \\
Cu/Zn-SOD & Sense & 5'-GCCTAGCGAGTTATGGCGACGA-3' \\
& Antisense & 5'-GGCCTCAGACTACATCCAAGG-3' \\
Catalase & Sense & 5'-CAGATGGACATCGCCACATG-3' \\
& Antisense & 5'-AAGACCAGTTTACCAACTGGG-3' \\
GPx1 & Sense & 5'-TGGCTTCTTGGACAATTGCG-3' \\
& Antisense & 5'-CCACCAGGAACTTCTCAAAG-3' \\
$\beta$-actin & Sense & 5'-CCTTCCTGGGCATGGAGTCCTG-3' \\
& Antisense & 5'-GGAGCAATGATCTTGATCTTC-3' \\
& & 27 \\
& & 27
\end{tabular}

B, Conditions for PCR

\begin{tabular}{|c|c|c|c|c|c|c|}
\hline \multirow[b]{2}{*}{ Target mRNA } & \multicolumn{2}{|c|}{ Denaturation reaction } & \multicolumn{2}{|c|}{ Annealing reaction } & \multicolumn{2}{|c|}{ Extension reaction } \\
\hline & Temperature $\left({ }^{\circ} \mathrm{C}\right)$ & Time (sec) & Temperature $\left({ }^{\circ} \mathrm{C}\right)$ & Time (sec) & Temperature $\left({ }^{\circ} \mathrm{C}\right)$ & Time (sec) \\
\hline Cox-2 & 94 & 30 & 58 & 30 & 72 & 30 \\
\hline $\mathrm{HO}-1$ & 94 & 60 & 65 & 60 & 72 & 60 \\
\hline Mn-SOD & 94 & 60 & 62 & 60 & 72 & 60 \\
\hline $\mathrm{Cu} / \mathrm{Zn}-\mathrm{SOD}$ & 94 & 60 & 65 & 60 & 72 & 120 \\
\hline Catalase & 94 & 60 & 55 & 120 & 72 & 180 \\
\hline GPx1 & 94 & 60 & 55 & 120 & 72 & 180 \\
\hline$\beta$-actin & 94 & 45 & 60 & 45 & 72 & 120 \\
\hline
\end{tabular}

Measurement of intracellular ROS levels. Intracellular ROS levels were analyzed using DCFH-DA as a ROS-reactive fluorescence probe as described previously $(24,26)$. In brief, after treatment with $0.3 \mu \mathrm{M}$ PDTC for 3 or $12 \mathrm{~h}$, cells $\left(1 \times 10^{6}\right.$ cells) were suspended in $1 \mathrm{ml}$ of PBS with $5 \mathrm{mM}$ DCFH-DA and incubated for $20 \mathrm{~min}$ at $37^{\circ} \mathrm{C}$. Next, cells were washed with PBS twice, and resuspended in $500 \mu \mathrm{l}$ of $2 \mu \mathrm{g} / \mathrm{ml}$ PI/PBS. The mean fluorescence intensity (MFI) of DCF green fluorescence from $3 \times 10^{4}$ cells were acquired for flow cytometry analysis using a FACSCanto flow cytometer and Diva software.

Statistical analysis. Data were analyzed using Student's t-test and $\mathrm{p}<0.05$ was considered as statistically significant.

\section{Results}

Cytocidal effects of PDTC on SCLC cell lines. After the treatment with various concentrations of PDTC $(0.1,1$ and $10 \mu \mathrm{M})$ for $24 \mathrm{~h}$, a significant decrease in cell viability was observed in a dose-dependent manner in NCI-H196 cells with $\mathrm{IC}_{50}$ value of $0.3 \mu \mathrm{M}$ (Fig. 1A). On the other hand, although PDTC also exhibited dose-dependent cytotoxic activity against NCI-H889, the $\mathrm{IC}_{50}$ value of PDTC could not be calculated from its proliferation inhibition curve since $>50 \%$ of cells survived even when treated with the highest concentration of PDTC $(10 \mu \mathrm{M})$ (Fig. 1A), indicating NCI-H196 is more sensitive to the cytotoxicity of PDTC compared to NCI-H889. Moreover, no apparent cytotoxic activity was observed in normal human embryonal lung fibroblast MRC-5 when treated with the same range of PDTC concentrations even for $48 \mathrm{~h}$ (Fig. 1B). No DNA fragmentation was observed in either SCLC cell line, indicating no involvement of apoptosis induction in the PDTCmediated cytotoxicity (Fig. 1C).

Effects of PDTC on cell cycle of SCLC cell lines. S phase arrest along with a significant decrease in the number of cells in $\mathrm{G}_{2} / \mathrm{M}$ phase was observed in NCI-H196 cells after treatment with the $\mathrm{IC}_{50}$ value of PDTC at $0.3 \mu \mathrm{M}$ for $24 \mathrm{~h}$ (Fig. 2A). 
(A)
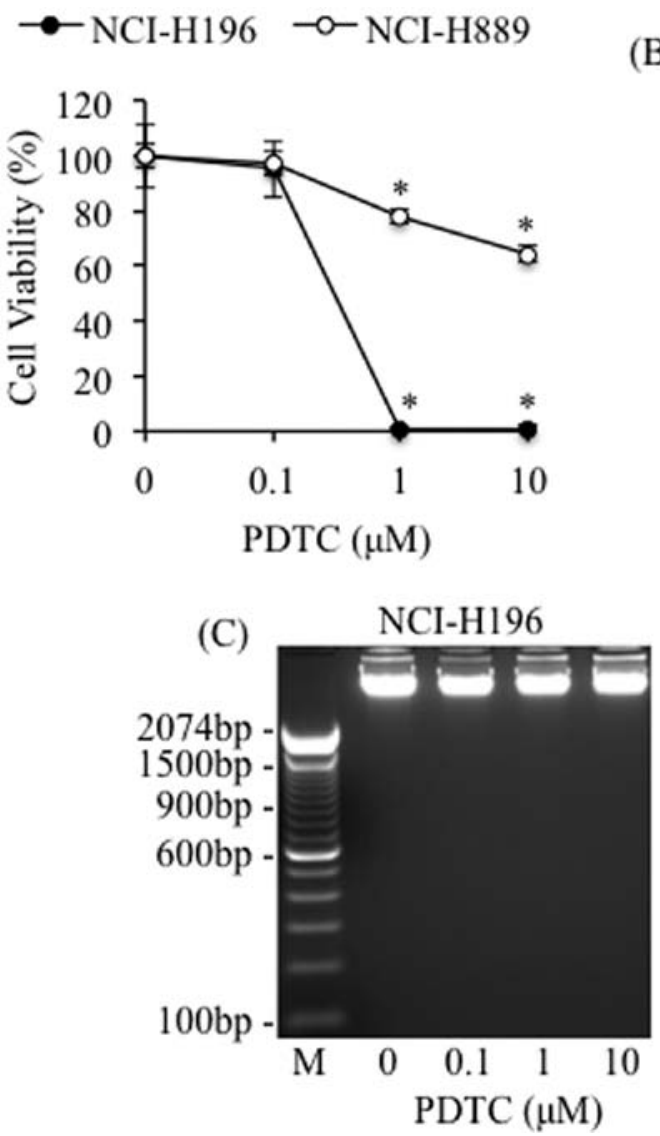

(B)
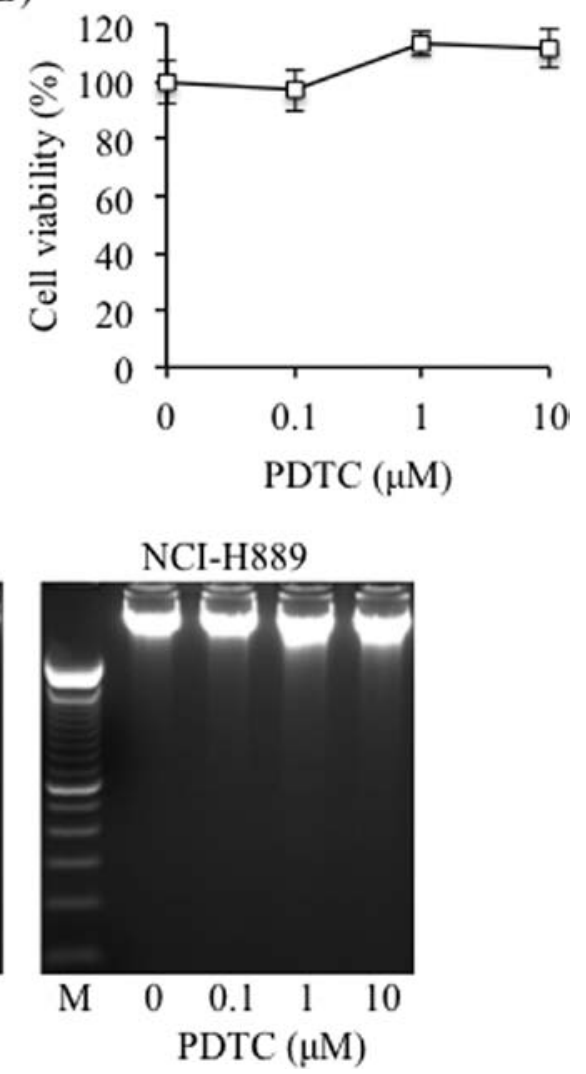

Figure 1. Cytocidal effects of PDTC on SCLC cell lines. After treatment of SCLC cell lines [NCI-H196 (•) and NCI-H889 (O)] (A) and MRC-5 (B) with various concentrations of PDTC $(0.1,1$ and $10 \mu \mathrm{M})$ for 24 and $48 \mathrm{~h}$, respectively, the cytotoxicity was analyzed by XTT assay as described in Materials and methods. Data are shown as the means and SD from three independent experiments [ ${ }^{*} \mathrm{p}<0.001$ vs. control $(0 \mu \mathrm{M}$ PDTC)]. (C) A representative pattern of DNA electrophoresis from three separate experiments is shown after treatment with indicated concentrations of PDTC for $24 \mathrm{~h}$. Lane M shows 100 -bp DNA size markers.

However, no apparent alterations of cell cycle were observed in NCI-H889 cells under the same treatment conditions (Fig. 2B). Furthermore, in agreement with the results presented in Fig. $1 C$, no significant accumulation of cells in sub- $G_{1}$ phase was observed in the treated cells (Fig. 2).

Suppression of c-myc expression in PDTC-treated NCI-H196 cells. A large body of physiological evidence has shown that either upregulation or downregulation of c-myc activity has profound consequences on cell cycle progression $(27,28)$. Therefore, the alteration of c-myc gene expression was evaluated in NCI-H196 cells after treatment with $0.3 \mu \mathrm{M}$ of PDTC for $12 \mathrm{~h}$. As shown in Fig. 3, the expression level of c-myc gene was significantly suppressed in PDTC-treated cells when compared to that in untreated cells. Furthermore, similar phenomena were not observed in NCI-H889 cells (data not shown).

Alteration of intracellular ROS levels in PDTC-treated $S C L C$ cell lines. Since the pro-oxidant activity of PDTC has been described to induce growth inhibition and cell death in different types of cancer cells $(10,11)$, intracellular ROS levels were evaluated in both SCLC cell lines after treatment with $0.3 \mu \mathrm{M}$ of PDTC for 3 and $12 \mathrm{~h}$. FACS analysis using DCFH-DA as a ROS-reactive fluorescence probe showed that a transient increase in the intracellular ROS levels was observed in NCI-H196 cells at 3-h post-treatment, followed by restoration to the control levels at 12-h post-treatment (Fig. 4A). On the other hand, a slight, but non-significant, increase in the accumulation of intracellular ROS was observed in NCI-H889 cells after treatment with PDTC for $3 \mathrm{~h}$ (Fig. 4B).

Expression profiles of oxidative stress-related mRNAs in PDTC-treated NCI-H196 cells. Since a transient increase in the intracellular ROS levels was observed in PDTC-treated NCI-H196 cells, expression profiles of oxidative stress-related gene mRNAs were evaluated in the cells after treatment with 0.3 and $1 \mu \mathrm{M}$ of PDTC for $1,3,6$ and $12 \mathrm{~h}$, respectively. It should be noted that the expression profiles of these gene mRNAs in cells treated with $0.3 \mu \mathrm{M}$ PDTC were very similar to those in cells treated with $1 \mu \mathrm{M}$ PDTC. As shown in Fig. 5A and $\mathrm{B}$, a significant increase in the expression level of Cox-2, which is known to play a central role in ROS production (29), was observed $6 \mathrm{~h}$ after treatment with PDTC, and the increase continued up to $12 \mathrm{~h}$. Furthermore, the expression of HO-1, which is closely associated with oxidative stress mediated cellular damage $(30,31)$, was significantly induced from as early as $3 \mathrm{~h}$ after the treatment with PDTC. In comparison to untreated cells, the level of HO-1 gene expression increased approximately 6- or 9-fold after 6- and 12-h treatment, respectively. Moreover, a significant decrease in the expression levels of Mn-SOD and $\mathrm{Cu} / \mathrm{Zn}$-SOD was observed $3 \mathrm{~h}$ after treatment 
(A) NCI-H196 cells
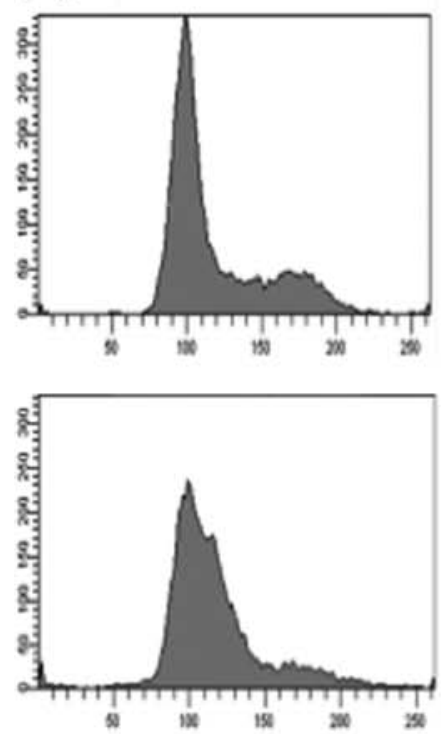

(B) NCI-H889 cells
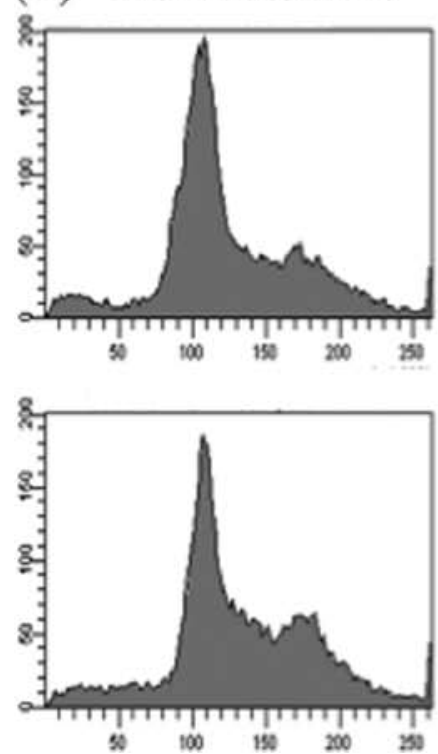

\section{$\square$ Control $\quad \square$ PDTC $0.3 \mu \mathrm{M}$}

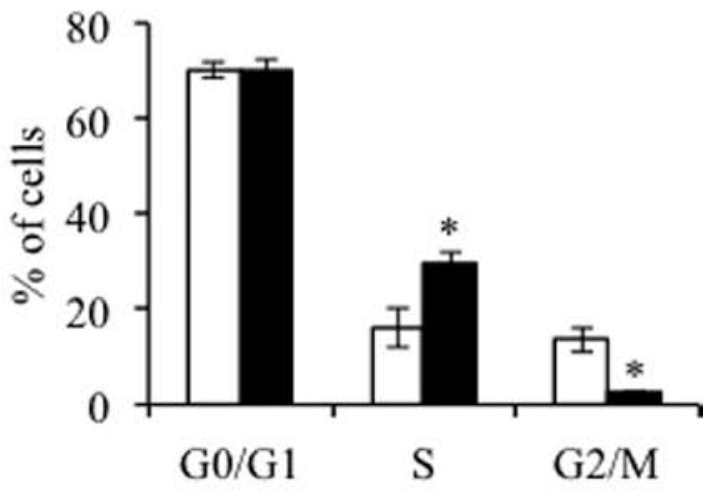

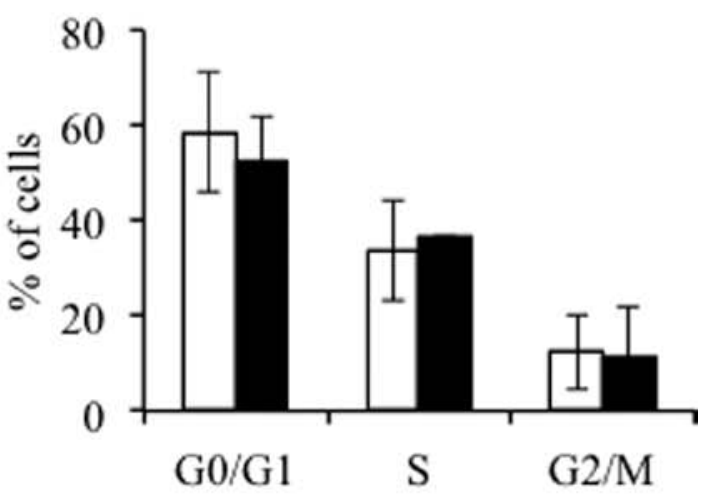

Figure 2. Effects of PDTC on cell cycle of SCLC cell lines. After treatment of NCI-H196 (A) and NCI-H889 (B) with $0.3 \mu \mathrm{M} \mathrm{PDTC} \mathrm{for} 24 \mathrm{~h}$, cell cycle analysis was performed using a FACSCanto flow cytometer as described in Materials and methods. A representative FACS histogram from three separate experiments is shown. Results are shown as the means $\pm \mathrm{SD}$ of three separate experiments ( $\mathrm{p}<0.01 \mathrm{vs}$. control).
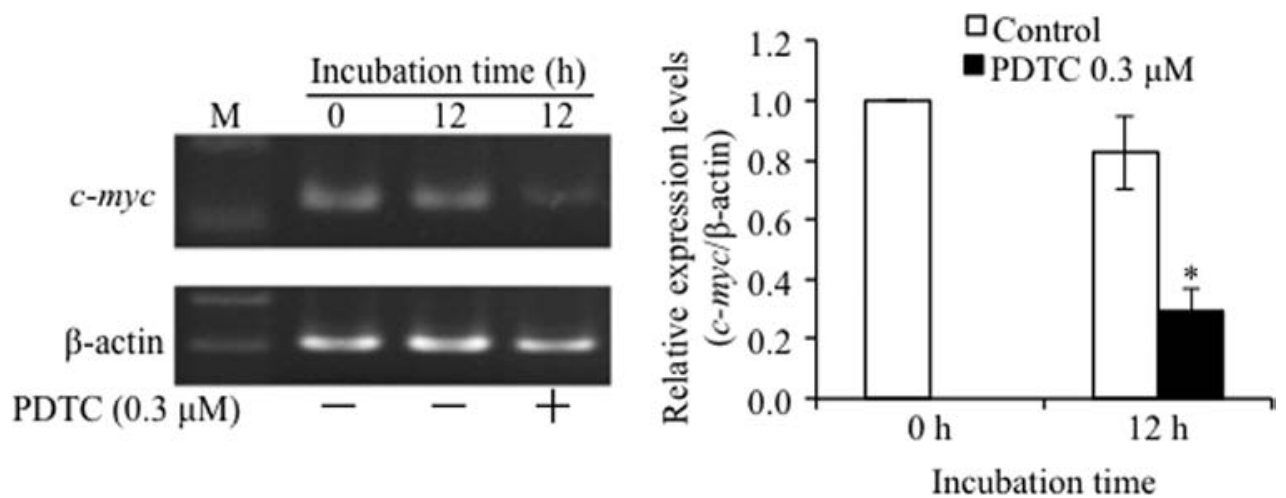

Figure 3. Suppression of c-Myc expression in PDTC-treated NCI-H196 cells. After the treatment with $0.3 \mu \mathrm{M}$ PDTC for $12 \mathrm{~h}$, the expression profile of c-myc mRNA was assessed by RT-PCR, followed by an agarose gel electrophoresis as described in Materials and methods. The relative expression levels of $\mathrm{c}-\mathrm{myc} / \beta$-actin gene were calculated as the ratios against those at 0 -time using ImageJ $1.46 \mathrm{~m}$. Results are shown as the means $\pm \mathrm{SD}$ of three separate experiments ("p $<0.05$ vs. control). 
(A) NCI-H196

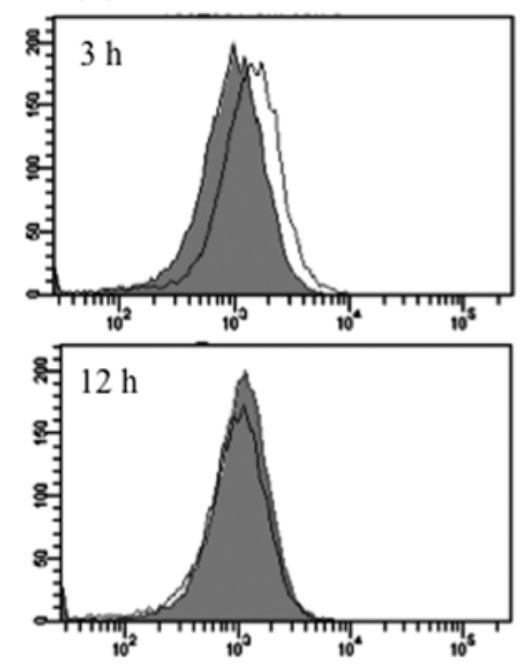

(B) NCI-H889
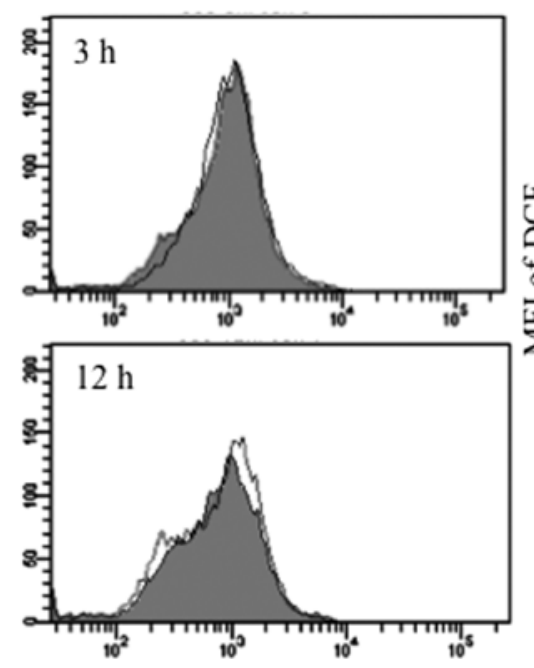
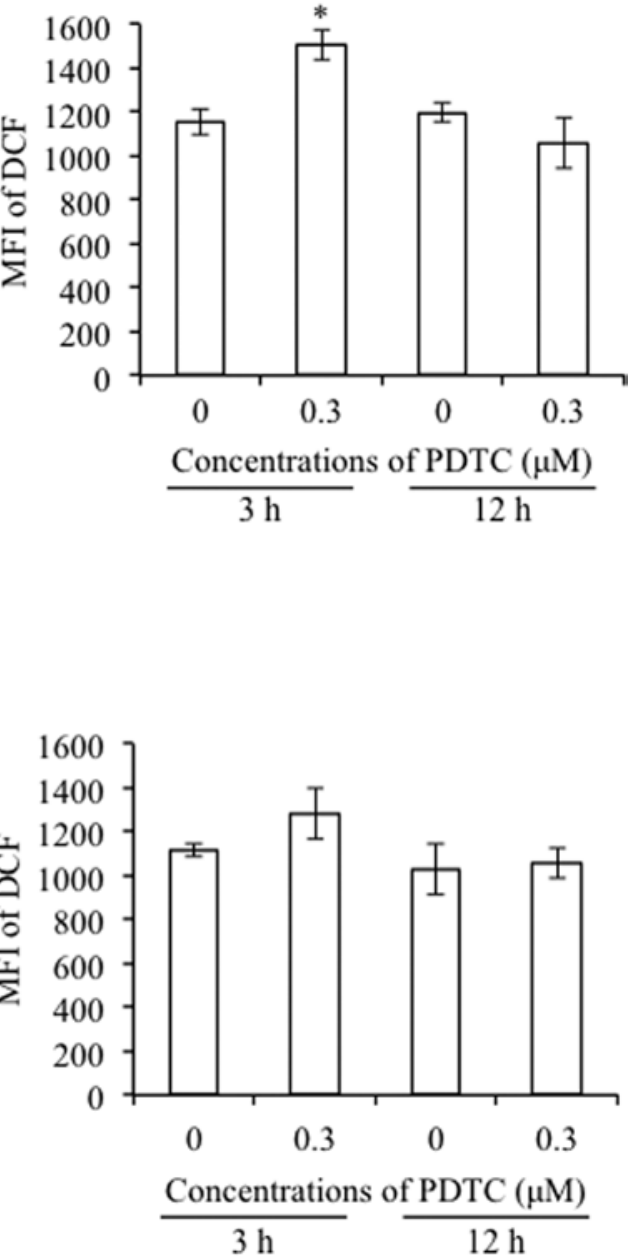

Figure 4. Alteration of intracellular ROS levels in PDTC-treated SCLC cell lines. After treatment of NCI-H196 (A) and NCI-H889 (B) with 0.3 $\mu$ M PDTC for 3 and $12 \mathrm{~h}$, respectively, alteration of intracellular ROS levels were analyzed using DCFH-DA as described in Materials and methods. ROS levels are presented as the mean fluorescence intensity (MFI) of DCF, an oxidation product of DCFH-DA. Results are shown as the means \pm SD of three separate experiments ( $\mathrm{p}<0.01$ vs. control).

with PDTC, and continued up to $12 \mathrm{~h}$. A slight but significant downregulation in catalase expression was observed $1 \mathrm{~h}$ after treatment with PDTC, followed by a substantial decrease at 3- and 6-h post-treatment. Similar to the expression of other antioxidant enzymes, the expression levels of GPx1 were also significantly downregulated at 6 - and 12 -h post-treatment, respectively. Moreover, PDTC-mediated alterations in expression level of the above-mentioned oxidative-related genes were abolished by the addition of $2 \mathrm{mM}$ NAC, a free radical scavenger (Fig. 5C). However, similar phenomena were not observed in NCI-H889 cells, except the behavior of HO-1 gene expression (data not shown).

Blocking of PDTC-induced cytotoxicity by NAC. To further verify whether oxidative stress is responsible for the cytotoxicity of PDTC against SCLC cell lines, we investigated the effects of NAC on the PDTC-induced cytotoxicity in NCI-H196 cells. As shown in Fig. 6A, dose-dependent cytotoxic effects of
PDTC on NCI-H196 cells were reconfirmed by the reduction in cell viability. Furthermore, the cells treated with $0.3 \mu \mathrm{M}$ PDTC for $24 \mathrm{~h}$ displayed apparent morphological changes such as shrinkage, spherical morphology, and detachment of the cells (Fig. 6B). In contrast, PDTC-induced reduction in cell viability and morphological changes were almost completely abrogated by the addition of 1 or 2 mM NAC (Fig. 6).

Inhibition of enhanced cytotoxicity of PDTC in combination with $\mathrm{CuCl}_{2}$ by $\mathrm{BCPS}$. As shown in Fig. 7, no cytocidal effects was observed in either of the SCLC cell lines after treatment with $0.1 \mu \mathrm{M}$ PDTC alone for $24 \mathrm{~h}$, consistent with the results in Fig. 1. However, a significant decrease in cell viability was observed in both cells after treatment with $0.1 \mu \mathrm{M}$ PDTC in combination with $10 \mu \mathrm{M} \mathrm{CuCl}_{2}$. Furthermore, a much stronger cytocidal effect against NCI-H196 cells was confirmed. Intriguingly, the addition of $50 \mu \mathrm{M}$ BCPS, a non-permeable copper-specific chelator, completely abrogated the enhanced 
A

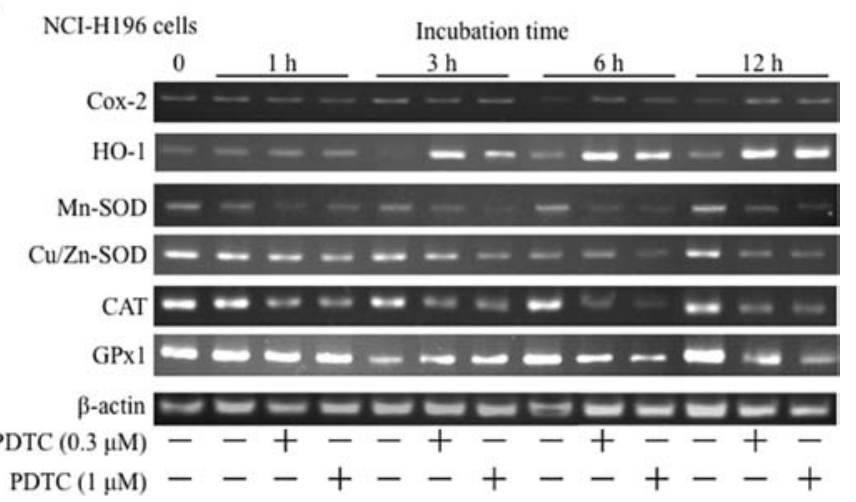

C $\mathrm{NCl}-\mathrm{H} 196$ cells

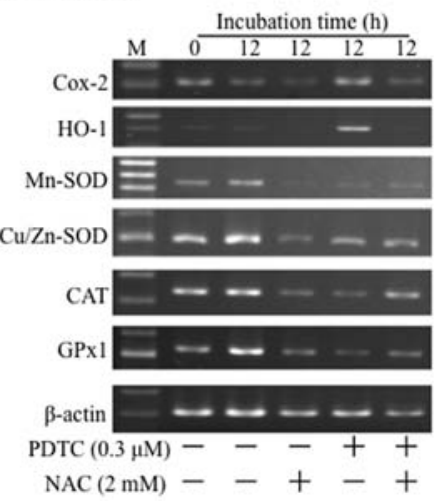

B $\multimap-$ Control $\rightarrow-$ PDTC $0.3 \mu \mathrm{M} \rightarrow-$ PDTC $1 \mu \mathrm{M}$
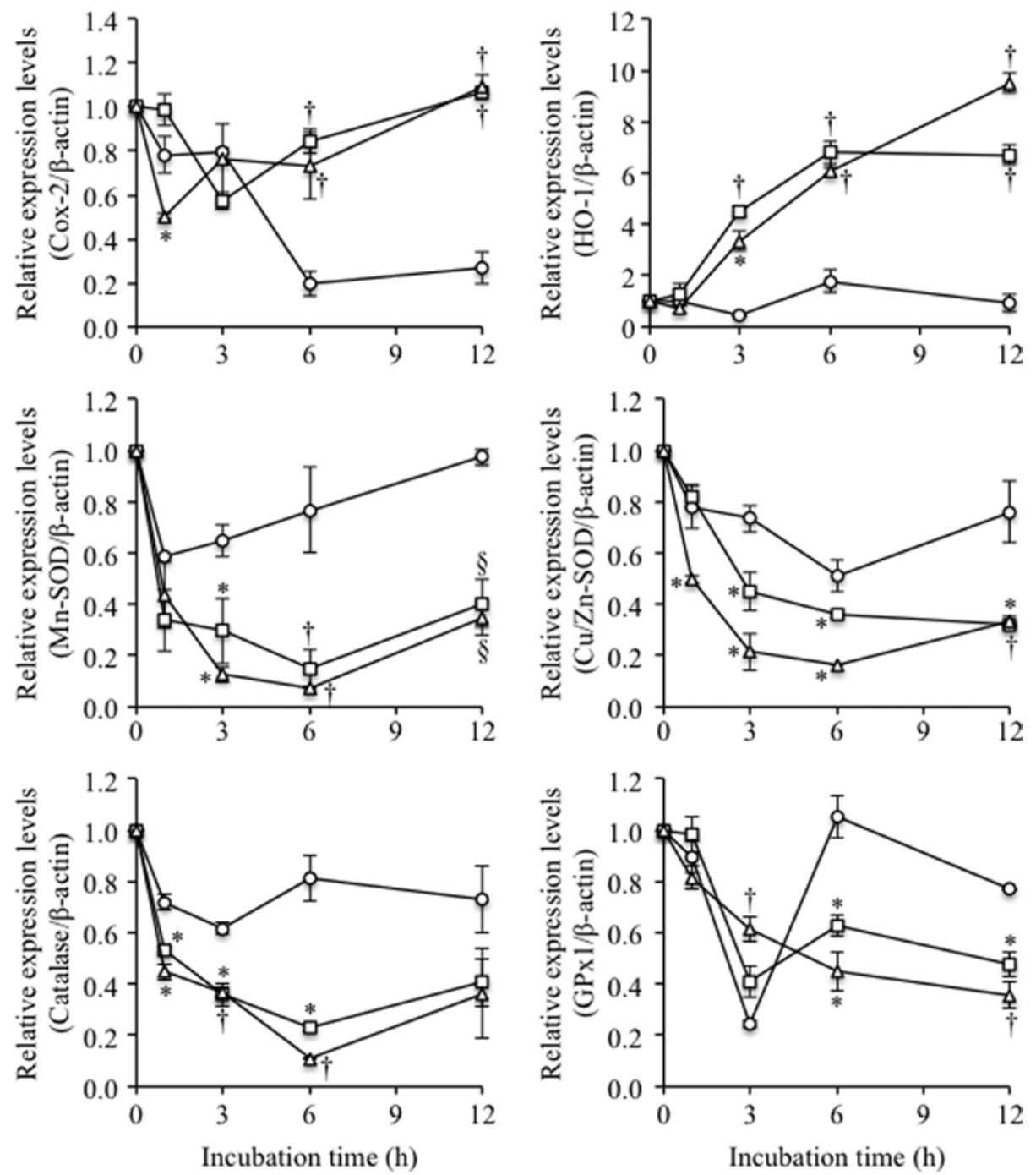

Figure 5. Expression profiles of oxidative stress-related mRNAs in PDTC-treated NCI-H196 cells. (A and C) The expression levels of oxidative stress-related mRNAs were analyzed by RT-PCR, followed by an agarose gel electrophoresis as described in Materials and methods. (B) The relative expression levels of each target gene/ $\beta$-actin gene were determined as described in Fig. 3 . Results are shown as the means \pm SD of three separate experiments $\left({ }^{*} \mathrm{p}<0.05\right.$; ${ }^{\dagger} \mathrm{p}<0.01$; ${ }^{\S} \mathrm{p}<0.001$ vs. control).

cytotoxicity of PDTC in combination with $\mathrm{CuCl}_{2}$. Moreover, after treatment $0.3 \mu \mathrm{M}$ PDTC alone for $24 \mathrm{~h}$, a significant decrease in the cell viability was observed in NCI-H196, but not in NCI-H889, reconfirming that NCI-H196 is more sensi- tive to the cytotoxicity of PDTC. Similarly, the addition of $50 \mu \mathrm{M}$ BCPS completely abrogated $0.3 \mu \mathrm{M}$ PDTC-mediated cytotoxicity in NCI-H196 cells. When both cells were treated with $0.3 \mu \mathrm{M}$ PDTC combined with $10 \mu \mathrm{M} \mathrm{CuCl}_{2}$, the enhanced 
(A)

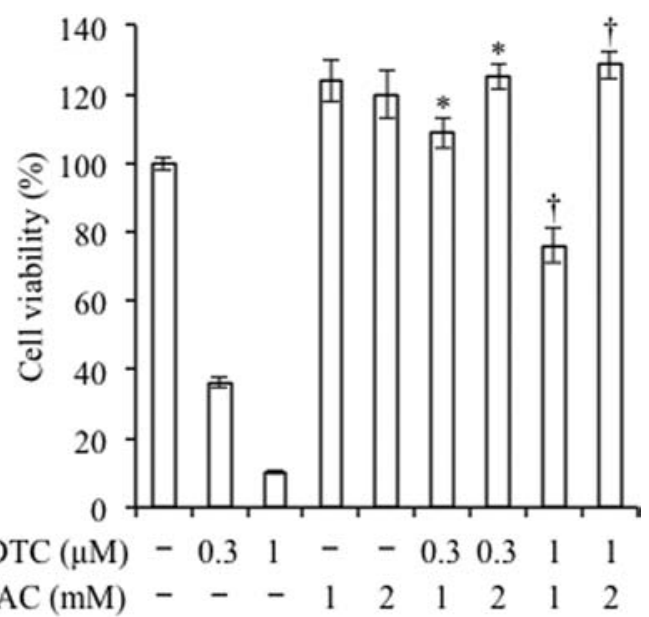

(B)

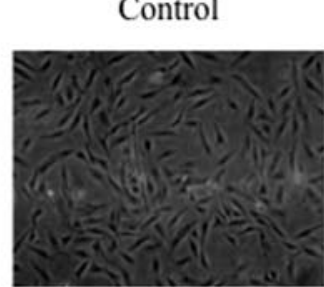

$\operatorname{NAC}(2 \mathrm{mM})$

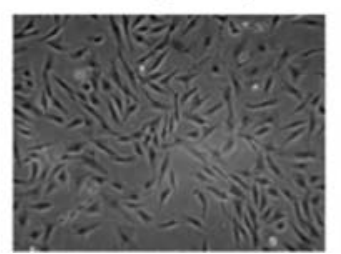

$\operatorname{PDTC}(0.3 \mu \mathrm{M})$

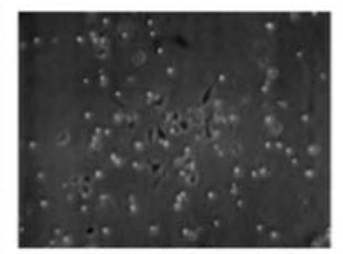

$\operatorname{PDTC}(0.3 \mu \mathrm{M})$

$\operatorname{NAC}(2 \mathrm{mM})$

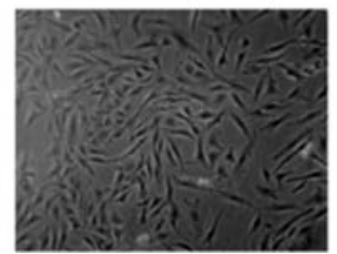

Figure 6. Blocking of PDTC-induced cytotoxicity by NAC. (A) After treatment with 0.3 and $1 \mu \mathrm{M}$ PDTC for $24 \mathrm{~h}$ in the presence or absence of NAC ( 1 or $2 \mathrm{mM})$, the cytotoxicity was analyzed by XTT assay as described in Materials and methods. Results are shown as the means \pm SD of three separate experiments ( $\mathrm{p}<0.001$ vs. $0.3 \mu \mathrm{M}$ PDTC; ${ }^{\dagger} \mathrm{p}<0.001$ vs. $1 \mu \mathrm{M}$ PDTC). (B) Morphological changes were observed by a phase contrast microscope (Olympus CK2) (x100).

\section{- $\mathrm{NCI}-\mathrm{H} 196 \quad \square_{\mathrm{NCl}-\mathrm{H} 889}$}

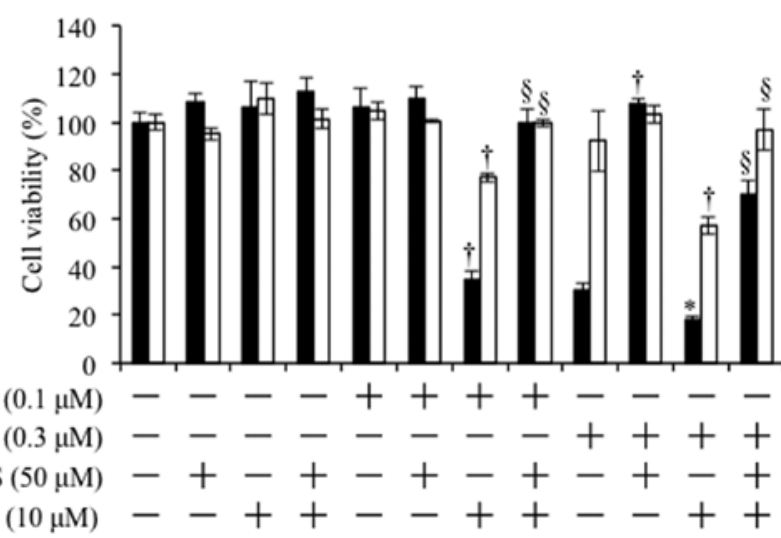

Figure 7. Inhibition of enhanced cytotoxicity of PDTC in combination with $\mathrm{CuCl}_{2}$ by BCPS in SCLC cell lines. After the treatment with each reagent, alone or in combination as indicated, for $24 \mathrm{~h}$, the cytotoxicity was analyzed by XTT assay as described in Materials and methods. Results are shown as the means \pm SD of three separate experiments $\left({ }^{*} \mathrm{p}<0.01 ;{ }^{\dagger} \mathrm{p}<0.001 \mathrm{vs}\right.$. PDTC alone; ${ }^{\S} \mathrm{p}<0.001$ vs. PDTC $+\mathrm{CuCl}_{2}$ ).

cytotoxicity was significantly abrogated by the addition of $50 \mu \mathrm{M}$ BCPS. Moreover, no alteration in cell viability was observed in the cells when treated with BCPS and $\mathrm{CuCl}_{2}$, either alone or in combination.

Downregulation of expression levels of ATP7A in PDTCtreated NCI-H196 cells. It has been demonstrated that cellular oxidative stress induced by PDTC may be attributed to increased intracellular concentrations of $\mathrm{Cu}(9,32)$. Indeed, it has been clarified that treatment with a relatively high concentration of PDTC $(10-100 \mu \mathrm{M})$ markedly increased an intracellular concentrations of $\mathrm{Cu}$, and that the combination of PDTC $(0.1-1 \mu \mathrm{M})$ with $\mathrm{Cu}(1 \mu \mathrm{M})$ also significantly increased the concentrations of intracellular $\mathrm{Cu}$ in parallel with an enhanced cytotoxicity in HL-60 cells and rat thymocytes, respectively $(9,11)$. Therefore, the expression levels of ATP7A responsible for $\mathrm{Cu}$ efflux, and $\mathrm{CTR} 1$ responsible for $\mathrm{Cu}$ uptake were investigated in PDTC-treated SCLC cell lines. As shown in Fig. 8, in comparison to control at 24-h time-point, almost no alteration in the expression level of CTR1 was observed in the cells after treatment with $0.3 \mu \mathrm{M}$ PDTC for $24 \mathrm{~h}$, although there was a trend showing an increase in its expression level. On the other hand, the expression level of ATP7A significantly decreased by $>50 \%$ in NCI-H196 cells, whereas displayed a slight, but not significant, increase in NCI-H889 cells. Interestingly, the expression level of two $\mathrm{Cu}$ transporters appeared to be affected by medium change, since notable differences in their expression levels were observed in control groups between 0 - and 24-h time-points.

Enhancement of cytotoxicity in NCI-H196 cells treated with combination of cisplatin and PDTC. A correlation between the expression level of $\mathrm{Cu}$ transporters and the degree of the acquired resistance to platinum drug, known as a first line treatment for SCLC patients, suggested that $\mathrm{Cu}$ transporters play critical roles in regulation of sensitivity to platinum drugs (16,19-21). Since the results presented in Fig. 8 showed that treatment with a relatively low concentration of PDTC significantly downregulated the expression level of ATP7A in NCI-H196 cells, an investigation into the effects of the combination of cisplatin and PDTC on the cells were followed in the study. After the treatment of NCI-H196 cells with various concentrations of cisplatin alone for $24 \mathrm{~h}$, the relative cell viabilities were 85,70 and $25 \%$ of control for 5,10 , and $100 \mu \mathrm{M}$ cisplatin, respectively. Moreover, a significant decrease in the cell viability was only observed in NCI-H889 cells when treated with $100 \mu \mathrm{M}$ cisplatin (the value of cell viability, 51\%). Intriguingly, treatment with $5 \mu \mathrm{M}$ cisplatin in combination with non-toxic dose of $0.1 \mu \mathrm{M}$ PDTC decreased the cell viability of NCI-H196 by $\sim 50 \%$, showing a synergistic effect in augmenting cytotoxicity of cisplatin (Fig. 9). On the other hand, a slight decrease in the cell viability of NCI-H889 was observed (Fig. 9).

\section{Discussion}

In the present study, we demonstrated that PDTC exhibited a much stronger dose-dependent cytotoxic activity against NCI-H196 compared to NCI-H889 cells. Furthermore, S phase arrest along with a significant decrease in the number of cells 
A

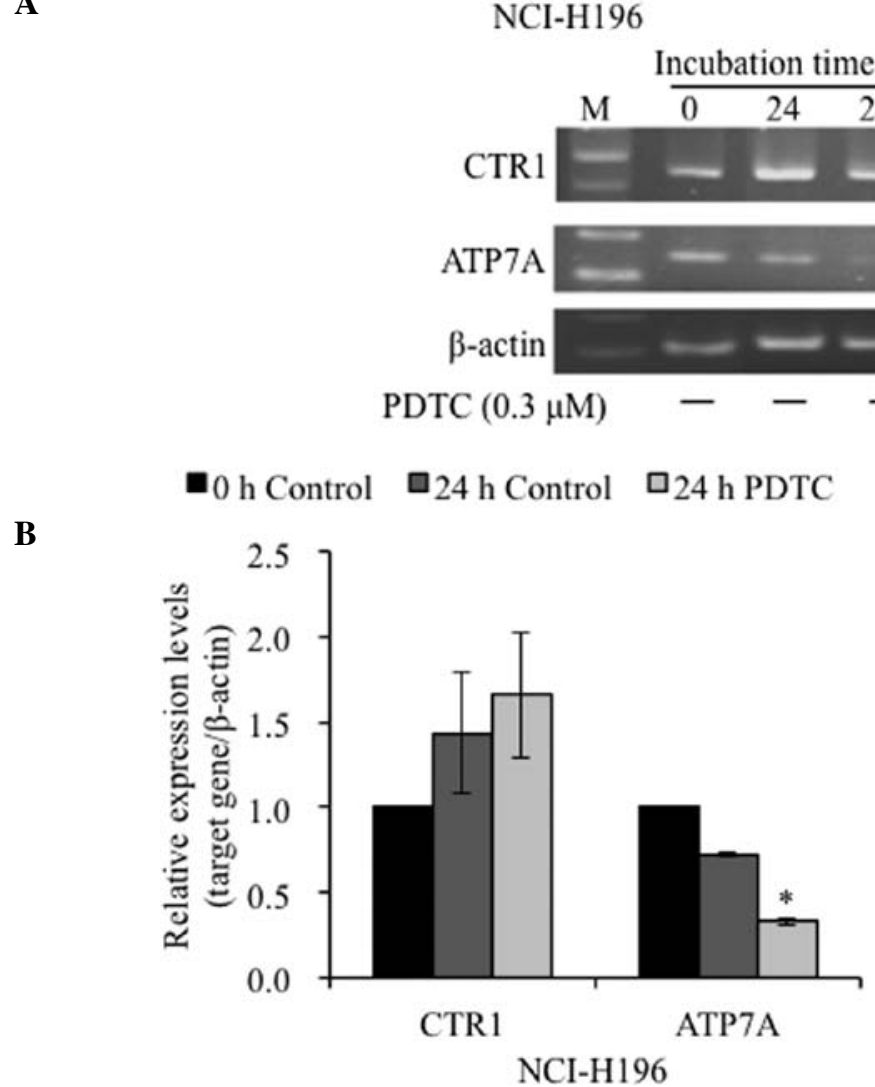

\section{NCI-H889}

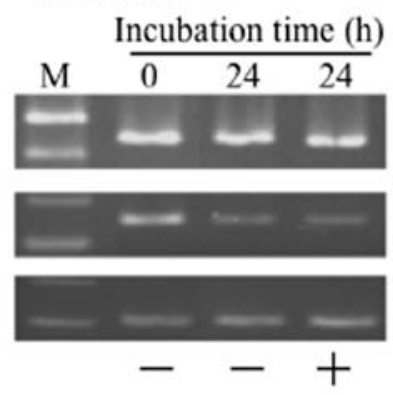

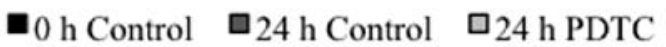

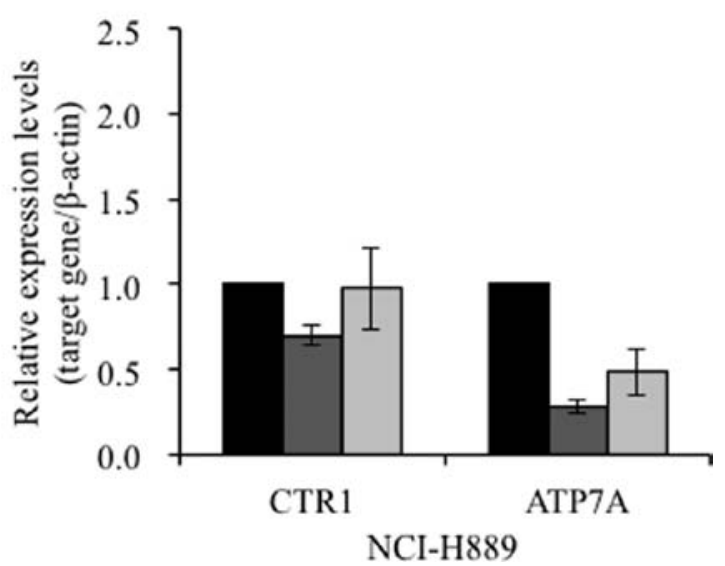

Figure 8. Downregulation of expression level of ATP7A in PDTC-treated NCI-H196 cells. (A) The expression level of Cu transporters including CTR1 and ATP7A mRNAs was analyzed by RT-PCR, followed by an agarose gel electrophoresis as described in Materials and methods. (B) The relative expression levels of each target gene/ $\beta$-actin gene were determined as described in Fig. 3 . Results are shown as the means \pm SD of three separate experiments $(* \mathrm{p}<0.001$ vs. control).

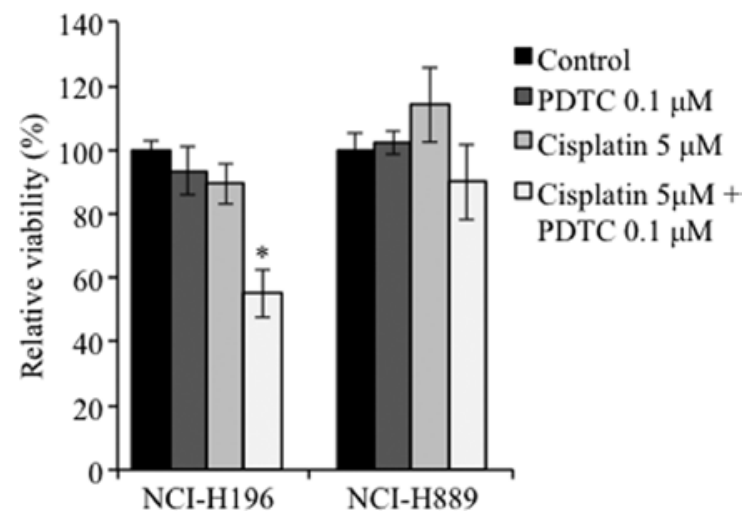

Figure 9. Enhancement of cytotoxicity in NCI-H196 cells treated with combination of cisplatin and PDTC. After treatment with $5 \mu \mathrm{M}$ cisplatin and $0.1 \mu \mathrm{M}$ PDTC, alone or in combination, the cytotoxicity was analyzed by XTT assay as described in Materials and methods. Results are shown as the means \pm SD of three separate experiments $\left({ }^{*} \mathrm{p}<0.01\right.$ cisplatin vs. cisplatin+PDTC).

in $\mathrm{G}_{2} / \mathrm{M}$ phase, but not DNA fragmentation, was observed in NCI-H196 cells. These results suggest that PDTC induces cytotoxicity in the SCLC cells via cell cycle arrest in the $\mathrm{S}$-phase, rather than apoptosis induction. Similar phenomena have also been observed in PDTC-treated human pancreatic adenocarcinoma cell line, $\mathrm{PaCa} 44$ (10). Interestingly, it has been demonstrated that NCI-H889 is more sensitive to the cytotoxicity of ABT-737, a small-molecule inhibitor of Bcl-2,
Bcl-XL, and Bcl-w (33), compared to NCI-H196, due to NCI-H889 having much higher Bcl-2 gene copy number (34). Therefore, the differential sensitivities of the two SCLC cell lines to PDTC may not be attributed to the different amounts of Bcl-2 gene number. Furthermore, consistent with previous findings showing that normal primary cells including human bone marrow $\mathrm{CD} 34^{+}$cells and fibroblasts are insensitive to the cytocidal effects of PDTC (10,35), we demonstrated that no alteration was observed in cell viability of the human MRC-5 embryonal lung fibroblasts when treated with toxic doses of PDTC in SCLC cell lines. These findings imply that normal cells are equipped with mechanisms by which they respond differently to PDTC effects with respect to tumor cells, providing further supportive evidence for the use of PDTC in wide clinical practice.

We further demonstrated that suppression of c-myc gene expression was observed in PDTC-treated NCI-H196 cells. It has been demonstrated that c-Myc is a critical protein in controlling proliferation, differentiation and survival of cancer cells $(27,28,36)$. It was demonstrated (28) that c-Myc downregulation caused by resveratrol, a plant polyphenol naturally occurring in grapes with chemopreventive properties (37), resulted in cell cycle arrest at $\mathrm{S}$ phase and apoptotic cell death in human medulloblastoma cells. It was further clarified that transfection of c-myc directed antisense oligonucleotides to the cells reduced c-myc expression, and consequently inhibited cell growth concomitant with cell cycle arrest in the $\mathrm{S}$ phase 
(28). Taken together, we suggested that c-myc downregulation is a critical molecular event in PDTC-mediated cell cycle arrest of NCI-H196 cells. In fact, a previous report demonstrated that treatment of leukemic cell line U-937 with $100 \mu \mathrm{M}$ of PDTC markedly downregulated the expression level of c-myc, associated with cell growth inhibition (38). Furthermore, Donadelli et al have demonstrated that PDTC induced P21 $1^{\text {WAFI/CIPI }}$ expression post-transcriptionally via a ROS/ERK mediated mechanism in $\mathrm{PaCa} 44$ cells, and consequently resulted in cell cycle arrest at $\mathrm{S}$ phase (10). It should be noted that $\mathrm{c}-m y c$ has been reported to be a negative regulator of $\mathrm{P} 21^{\text {WAFI/CIPI }}$ expression in lung cancer cells (39). Therefore, further studies may be needed to clarify the molecular details of correlation between c-myc and $\mathrm{P} 21^{\text {WAFII }}$ ${ }_{C I P I}$ in PDTC-treated SCLC cell lines.

We also demonstrated that PDTC induced accumulation of intracellular ROS in NCI-H196 cells, paralleled with an alteration of oxidative stress-related gene expression, suggesting that PDTC acts as a pro-oxidant agent in the cells, although the antioxidant activity of PDTC has been reported to induce cytotoxicity in some tumor cell lines, such as colorectal (4) and prostatic carcinoma cells (5). In line with these results, the addition of NAC, a free radical scavenger, not only abolished PDTC-triggered alterations of the above-mentioned oxidative stress-related gene expression but also almost completely abrogated PDTC-induced reduction in cell viability and morphological changes associated with cell damage.

In agreement with a previous report showing that combination treatment with $\mathrm{CuCl}_{2}$ and PDTC enhanced the cytocidal effects against HL-60 cells (11), we also demonstrated that a significant decrease in cell viability was observed in SCLC cell lines after treatment with $0.1 \mu \mathrm{M}$ PDTC in combination with $10 \mu \mathrm{M} \mathrm{CuCl}_{2}$, either of which was a non-toxic dose. Interestingly, BCPS, a non-permeable copper-specific chelator, completely abrogated the enhanced cytotoxicity of PDTC in combination with $\mathrm{CuCl}_{2}$. In this regard, BCPS has been demonstrated to block the penetration of $\mathrm{Cu}$ into cells and prevent $\mathrm{Cu}$ overload, and consequently protect HL-60 cells from the cytotoxicity caused by PDTC/Cu complex (11). Furthermore, it has been demonstrated that cellular oxidative stress induced by PDTC may be attributed to an increased intracellular concentrations of $\mathrm{Cu}$ due to ionophore activity of PDTC $(6,9,32)$. Taking these previous results and our observations into account, we suggested that PDTC induced cytocidal effects against SCLC cell lines by raising intracellular levels of $\mathrm{Cu}$, known to be responsible for ROS generation via Fenton reaction $(32,40)$.

Intriguingly, after treatment with PDTC, the expression level of ATP7A, a copper export protein responsible for maintaining copper homeostasis (16,19-21), significantly decreased in NCI-H196 cells, whereas almost no alteration was observed in the expression level of CTR1 responsible for copper uptake (16). Although the detailed mechanisms underlying the downregulation of the expression level of ATP7A are need to clarify, these results provide a new rationale for the clinical use of PDTC since expression of ATP7A has been reportedly associated with platinum-drug resistance in various types of solid tumors (17-19). It is especially noteworthy that ATP7A overexpression plays an important role in platinum-resistance of NSCLC, and was a negative prognostic factor of NSCLC patients treated with platinum-based chemotherapy (20).
Furthermore, a recent study demonstrated that microRNA-495 enhanced the sensitivity of NSCLC cells to platinum-drug by modulation of ATP7A expression (21). Although PDTC has been demonstrated to sensitize different types of cancer cells by inhibiting transcription activity of NF- $\mathrm{KB}(12,13)$, the effects of PDTC on the expression of copper transporters still remains unclear. Therefore, our current findings suggest that PDTC can raise the intracellular level of $\mathrm{Cu}$ via downregulation of ATP7A expression, result in the accumulation of intracellular ROS, and consequently cause profound cytotoxicity in SCLC cell lines. Based on the fact that the expression of ATP7A is closely related with platinum-resistance in various types of solid tumors including lung cancer $(17,19-21,41)$, we further hypothesized that PDTC could probably be able to sensitize SCLC cells to cisplatin. As expected, combination of much lower dose of cisplatin $(5 \mu \mathrm{M})$ and non-toxic dose of PDTC $(0.1 \mu \mathrm{M})$ synergistically induced a significant cytotoxicity in NCI-H196 cells, the details of the study on the synergistic effects are current underway.

In conclusion, PDTC-induced cytocidal effects against SCLC cells were characterized by the $S$ phase arrest paralleled with suppression of c-myc expression. Furthermore, the cytotoxicity triggered by PDTC and $\mathrm{CuCl}_{2}$, alone or in combination, was significantly abrogated by the addition of BCPS. Importantly, the downregulation of ATP7A expression was observed for the first time in PDTC-treated NCI-H196 cells. These results support the plausibility that increased accumulation of intracellular $\mathrm{Cu}$ as a result of ATP7A inhibition plays an important role in PDTC-mediated cytotoxicity in SCLC cell lines, although its exact concentrations were not evaluated in the current study. Given that ATP7A plays a critical role in the resistance of platinum-drugs (such as cisplatin) representing the first-line treatment of SCLC, PDTC could be a promising candidate of adjunct therapeutic reagent for the patients requiring treatment with platinum-based regimens.

\section{Acknowledgements}

This study was supported in part by grants from the Ministry of Education, Culture, Sports, Science and Technology and by the Promotion and Mutual Aid Corporation for Private Schools of Japan.

\section{References}

1. Chan BA and Coward JI: Chemotherapy advances in small-cell lung cancer. J Thorac Dis 5: S565-S578, 2013.

2. van Meerbeeck JP, Fennell DA and De Ruysscher DK: Small-cell lung cancer. Lancet 378: 1741-1755, 2011.

3. Jackman DM and Johnson BE: Small-cell lung cancer. Lancet 366: 1385-1396, 2005.

4. Chinery R, Brockman JA, Peeler MO, Shyr Y, Beauchamp RD and Coffey RJ: Antioxidants enhance the cytotoxicity of chemotherapeutic agents in colorectal cancer: a p53-independent induction of p21 ${ }^{\mathrm{WAFI} / \mathrm{CIP1}}$ via C/EBPbeta. Nat Med 3: 1233-1241, 1997.

5. Herrmann JL, Beham AW, Sarkiss M, et al: Bcl-2 suppresses apoptosis resulting from disruption of the NF-kappa B survival pathway. Exp Cell Res 237: 101-109, 1997.

6. Chen SH, Liu SH, Liang YC, Lin JK and Lin-Shiau SY: Death signaling pathway induced by pyrrolidine dithiocarbamate$\mathrm{Cu}(2+)$ complex in the cultured rat cortical astrocytes. Glia 31: 249-261, 2000.

7. Forman HJ, York JL and Fisher AB: Mechanism for the potentiation of oxygen toxicity by disulfiram. J Pharmacol Exp Ther 212: $452-455,1980$. 
8. Goldstein BD, Rozen MG, Quintavalla JC and Amoruso MA Decrease in mouse lung and liver glutathione peroxidase activity and potentiation of the lethal effects of ozone and paraquat by the superoxide dismutase inhibitor diethyldithiocarbamate. Biochem Pharmacol 28: 27-30, 1979.

9. Nobel CI, Kimland M, Lind B, Orrenius S and Slater AF: Dithiocarbamates induce apoptosis in thymocytes by raising the intracellular level of redox-active copper. J Biol Chem 270: 26202-26208, 1995.

10. Donadelli M, Dalla Pozza E, Costanzo C, et al: Increased stability of P21(WAF1/CIP1) mRNA is required for ROS/ ERK-dependent pancreatic adenocarcinoma cell growth inhibition by pyrrolidine dithiocarbamate. Biochim Biophys Acta 1763: 917-926, 2006.

11. Chen SH, Lin JK, Liang YC, Pan MH, Liu SH and Lin-Shiau SY: Involvement of activating transcription factors JNK, NF-kappaB, and AP-1 in apoptosis induced by pyrrolidine dithiocarbamate/ Cu complex. Eur J Pharmacol 594: 9-17, 2008.

12. Morais C, Gobe G, Johnson DW and Healy H: Inhibition of nuclear factor kappa B transcription activity drives a synergistic effect of pyrrolidine dithiocarbamate and cisplatin for treatment of renal cell carcinoma. Apoptosis 15: 412-425, 2010.

13. Venkatraman M, Anto RJ, Nair A, Varghese M and Karunagaran D: Biological and chemical inhibitors of NF-kappaB sensitize SiHa cells to cisplatin-induced apoptosis. Mol Carcinog 44: 51-59, 2005.

14. Evans WK, Shepherd FA, Feld R, Osoba D, Dang P and Deboer G: VP-16 and cisplatin as first-line therapy for small-cell lung cancer. J Clin Oncol 3: 1471-1477, 1985.

15. Sundstrom S, Bremnes RM, Kaasa S, et al: Cisplatin and etoposide regimen is superior to cyclophosphamide, epirubicin, and vincristine regimen in small-cell lung cancer: results from a randomized phase III trial with 5 years' follow-up. J Clin Oncol 20: 4665-4672, 2002

16. Safaei R: Role of copper transporters in the uptake and efflux of platinum containing drugs. Cancer Lett 234: 34-39, 2006.

17. Samimi G, Safaei R, Katano K, et al: Increased expression of the copper efflux transporter ATP7A mediates resistance to cisplatin, carboplatin, and oxaliplatin in ovarian cancer cells. Clin Cancer Res 10: 4661-4669, 2004.

18. Safaei R, Katano K, Samimi G, et al: Cross-resistance to cisplatin in cells with acquired resistance to copper. Cancer Chemother Pharmacol 53: 239-246, 2004

19. Inoue Y, Matsumoto H, Yamada S, et al: Association of ATP7A expression and in vitro sensitivity to cisplatin in non-small cel lung cancer. Oncol Lett 1: 837-840, 2010.

20. Li ZH, Qiu MZ, Zeng ZL, et al: Copper-transporting P-type adenosine triphosphatase (ATP7A) is associated with platinumresistance in non-small cell lung cancer (NSCLC). J Transl Med 10: 21,2012 .

21. Song L, Li Y, Li W, Wu S and Li Z: miR-495 enhances the sensitivity of non-small cell lung cancer cells to platinum by modulation of copper-transporting P-type adenosine triphosphatase A (ATP7A). J Cell Biochem 115: 1234-1242, 2014.

22. Imai M, Kikuchi H, Denda T, Ohyama K, Hirobe $\mathrm{C}$ and Toyoda H: Cytotoxic effects of flavonoids against a human colon cancer derived cell line, COLO 201: a potential natural anticancer substance. Cancer Lett 276: 74-80, 2009.

23. Yuan B, Ohyama K, Bessho T and Toyoda H: Contribution of inducible nitric oxide synthase and cyclooxygenase-2 to apoptosis induction in smooth chorion trophoblast cells of human fetal membrane tissues. Biochem Biophys Res Commun 341: 822-827, 2006.

24. Kikuchi H, Yuan B, Yuhara E, Takagi N and Toyoda $\mathrm{H}$ Involvement of histone $\mathrm{H} 3$ phosphorylation through $\mathrm{p} 38$ MAPK pathway activation in casticin-induced cytocidal effects against the human promyelocytic cell line HL-60. Int J Oncol 43: 2046-2056, 2013.
25. Kon A, Yuan B, Hanazawa T, et al: Contribution of membrane progesterone receptor alpha to the induction of progesteronemediated apoptosis associated with mitochondrial membrane disruption and caspase cascade activation in Jurkat cell lines. Oncol Rep 30: 1965-1970, 2013.

26. Hu XM, Yuan B, Tanaka S, et al: Involvement of oxidative stress associated with glutathione depletion and p38 mitogenactivated protein kinase activation in arsenic disulfide-induced differentiation in HL-60 cells. Leuk Lymphoma 55: 392-404, 2014.

27. Obaya AJ, Mateyak MK and Sedivy JM: Mysterious liaisons: the relationship between c-Myc and the cell cycle. Oncogene 18: 2934-2941, 1999.

28. Zhang P, Li H, Wu ML, et al: c-Myc downregulation: a critical molecular event in resveratrol-induced cell cycle arrest and apoptosis of human medulloblastoma cells. J Neurooncol 80: 123-131, 2006.

29. Payne CM, Bernstein C and Bernstein H: Apoptosis overview emphasizing the role of oxidative stress, DNA damage and signal-transduction pathways. Leuk Lymphoma 19: 43-93, 1995.

30. Keyse SM and Tyrrell RM: Heme oxygenase is the major 32-kDa stress protein induced in human skin fibroblasts by UVA radiation, hydrogen peroxide, and sodium arsenite. Proc Natl Acad Sci USA 86: 99-103, 1989.

31. Keyse SM and Tyrrell RM: Both near ultraviolet radiation and the oxidizing agent hydrogen peroxide induce a $32-\mathrm{kDa}$ stress protein in normal human skin fibroblasts. J Biol Chem 262: $14821-14825,1987$

32. Furuta S, Ortiz F, Zhu Sun X, Wu HH, Mason A and Momand J: Copper uptake is required for pyrrolidine dithiocarbamatemediated oxidation and protein level increase of p53 in cells. Biochem J 365: 639-648, 2002.

33. Oltersdorf T, Elmore SW, Shoemaker AR, et al: An inhibitor of Bcl-2 family proteins induces regression of solid tumours. Nature 435: 677-681, 2005

34. Olejniczak ET, Van Sant C, Anderson MG, et al: Integrative genomic analysis of small-cell lung carcinoma reveals correlates of sensitivity to bcl-2 antagonists and uncovers novel chromosomal gains. Mol Cancer Res 5: 331-339, 2007.

35. Malaguarnera L, Pilastro MR, DiMarco R, et al: Cell death in human acute myelogenous leukemic cells induced by pyrrolidinedithiocarbamate. Apoptosis 8: 539-545, 2003.

36. Cheng YC, Lin H, Huang MJ, Chow JM, Lin S and Liu HE: Downregulation of c-Myc is critical for valproic acid-induced growth arrest and myeloid differentiation of acute myeloid leukemia. Leuk Res 31: 1403-1411, 2007.

37. Jang M, Cai L, Udeani GO, et al: Cancer chemopreventive activity of resveratrol, a natural product derived from grapes. Science 275: 218-220, 1997.

38. Aragones J,Lopez-Rodriguez C, Corbi A, et al: Dithiocarbamates trigger differentiation and induction of CD11c gene through AP-1 in the myeloid lineage. J Biol Chem 271: 10924-10931, 1996.

39. Bae KM, Wang H, Jiang G, Chen MG, Lu L and Xiao L: Protein kinase $\mathrm{C}$ epsilon is overexpressed in primary human non-small cell lung cancers and functionally required for proliferation of non-small cell lung cancer cells in a p21/Cip1-dependent manner. Cancer Res 67: 6053-6063, 2007.

40. Lloyd DR and Phillips DH: Oxidative DNA damage mediated by copper(II), iron(II) and nickel(II) fenton reactions: evidence for site-specific mechanisms in the formation of double-strand breaks, 8-hydroxydeoxyguanosine and putative intrastrand cross-links. Mutat Res 424: 23-36, 1999.

41. Zhang H, Wu JS and Peng F: Potent anticancer activity of pyrrolidine dithiocarbamate-copper complex against cisplatinresistant neuroblastoma cells. Anticancer Drugs 19: 125-132, 2008. 